\title{
Congenital hypogonadotropic hypogonadism: from clinical characteristics to genetic aspects
}

\author{
Ahreum Kwon, Ho-Seong Kim \\ Division of Pediatric Endocrinology, Department of Pediatrics, Severance Children's Hospital and Institute of Endocrinology, \\ Yonsei University College of Medicine, Seoul, Korea
}

Received: July 30, 2021

Revised: August 26, 2021

Accepted: September 1, 2021

Corresponding author:

Ho-Seong Kim

Department of Pediatrics,

Severance Children's Hospital,

Endocrine Research Institute,

Yonsei University College

of Medicine, 50-1 Yonsei-ro,

Seodaemun-gu, Seoul 03722,

Korea

Tel: +82-2-2228-2069

E-mail:kimho@yuhs.ac

\begin{abstract}
Congenital hypogonadotropic hypogonadism $(\mathrm{CHH})$ is a rare disorder caused by a deficiency in gonadotropin-releasing hormone $(\mathrm{GnRH})$. $\mathrm{CHH}$ is characterized by delayed puberty and/or infertility; this is because GnRH is the main component of the hypothalamic-pituitary-gonadal (HPG) axis, which is a key factor in pubertal development and reproductive function completion. However, since the development of sexual characteristics and reproduction begins in the prenatal period and is very complex and delicate, the clinical characteristics and involved genes are very diverse. In particular, the HPG axis is activated three times in a lifetime, and the symptoms and biochemical findings of $\mathrm{CHH}$ vary by period. In addition, related genes also vary according to the formation and activation process of the HPG axis. In this review, the clinical characteristics and treatment of $\mathrm{CHH}$ according to HPG axis activation and different developmental periods are reviewed, and the related genes are summarized according to their pathological mechanisms.
\end{abstract}

Keywords: Cryptorchidism; Gonadotropin-releasing hormone; Hypogonadism; Infertility; Puberty, delayed

\section{INTRODUCTION}

Congenital hypogonadotropic hypogonadism $(\mathrm{CHH})$ is a rare disease with a prevalence of approximately 1:8,000 in men and 1:40,000 in women $[1,2]$. CHH is characterized by absent or incomplete sexual development and/or infertility due to gonadotropin-releasing hormone $(\mathrm{GnRH})$ deficiency $[1,3,4]$. Unlike acquired disease caused by damage to the pituitary gland and hypothalamus in which multiple pituitary/hypothalamic hormones are deficient, $\mathrm{CHH}$ is characterized by isolated GnRH deficiency [2]. However, because the hypothalamic-pituitary-gonadal (HPG) axis plays a key role in pubertal development and reproduction and because this process is extremely complex and begins in early fetal life, $\mathrm{CHH}$ reveals a broad range of clinical phenotypes in each patient. In addition, as high-throughput next generation sequencing (NGS) has been widely used in recent years, the causative genes of $\mathrm{CHH}$ are becoming increasingly known. Therefore, there is a trend to consider customized treatment ac-
This is an Open Access article distributed under the terms of the Creative Commons Attribution Non-Commercial License (https:// creativecommons.org/licenses/ by-nc/4.0/). 
cording to the clinical symptoms and causative genes of each patient. In this review, we will summarize the clinical characteristics, diagnosis, and treatment of $\mathrm{CHH}$ by the developmental period and classify the related genes according to their pathophysiologic mechanisms.

\section{NORMAL PHYSIOLOGICAL PROCESS OF SEXUAL DIFFERENTIATION AND PUBERTY DEVELOPMENT}

Pulsatile GnRH secretion in the hypothalamus stimulates the secretion of gonadotropins, including luteinizing hormone (LH) and follicle-stimulating hormone (FSH), which stimulate the gonads to develop, produce, and secrete gonadal hormones. In brief, LH stimulates the Leydig cells in the testes to produce testosterone and FSH stimulates the Sertoli cells to produce the anti-Müllerian hormone (AMH) in males. Testosterone is responsible for masculinizing the external genitalia, and AMH regresses Müllerian duct products such as the fallopian tubes, uterus, and upper vagina. In females, LH stimulates the theca cells in the ovaries to produce testosterone, which is converted to estradiol by FSH-induced aromatase activity in the granulosa cells [5]. Estradiol affects the development of secondary female sexual characteristics, developing breast tissues and mammary glands as well as increasing the size of the uterus [6]. In addition, FSH promotes the development of follicles and $\mathrm{LH}$ promotes ovulation in mature follicles while simultaneously forming a corpus luteum to promote the secretion of estrogen and progesterone. Therefore, if GnRH secretion and/or its action are defective, the results are gonadotropin deficiency and low levels of sex steroids, which lead to defects in the external genitalia, sexual maturation, and gametogenesis [2,7].

$\mathrm{GnRH} /$ gonadotropin secretion begins with the activation of the HPG axis, a very complex and delicate representative of puberty development and the completion of reproductive function. There are typically three phases of HPG axis activation in a lifespan: in fetal life during the second trimester of pregnancy, after birth at a postnatal age of 1 to 6 months, denoted mini-puberty, and during adolescence, when puberty begins [5].

\section{Fetal period}

Sex chromosomes (X or $Y$ ), especially the presence or absence of the sex-determining region of the $Y(S R Y)$ gene, determine genetic sex. $S R Y$ and its interacting genes determine the fate of primitive gonads in the testes or ovaries. That is, if
$S R Y$ and the genes involved in the gonadal development of testes are present, and if there are no genes present that inhibit the testicular development of gonads, the primitive gonads will develop into testes. In the absence of $S R Y$ and in the presence of associated genes for ovary development, primitive gonads become the ovaries. When the fate of the primitive gonads is determined as either testes or ovaries, the hormones secreted by each cell in the gonads induce the formation of the internal and external genitalia into male or female genitalia.

In males, primitive gonads differentiate into testes, and placental human chorionic gonadotropin (hCG) stimulates the Leydig cells to secrete testosterone during early gestation. From week 10 of gestation, pituitary LH levels, which also control the secretion of fetal testosterone, increase with peak levels similar to adult values between 11 and 14 weeks of gestation [8]. Testosterone levels increase along with changes in hCG and LH levels [8], and fetal testosterone is key to the virility of the external genitalia. Testosterone is converted to dihydrotestosterone by the enzyme 5-a reductase 2 for the development of the prostate, penis, and scrotum. LH also stimulates the secretion of insulin-like peptide 3 (INSL-3), which is associated with testes descent. Testicular descent is divided into two phases. The first phase, completed by 15 weeks of gestation, occurs intra-abdominally and is dependent on INSL-3 and not testosterone; meanwhile, the second phase, the inguinoscrotal phase, which is completed by 35 weeks of gestation, is androgen-dependent [9]. The changes in fetal FSH levels are similar to those of pituitary $\mathrm{LH}$, even though LH levels are significantly higher than FSH levels $[5,8]$. During fetal life, FSH stimulates the Sertoli cells to produce AMH, which regresses the Müllerian ducts [10]. Therefore, gonadotropin deficiency or absence of the HPG axis activation during male fetal development can lead to the occurrence of cryptorchidism and/or the development of a micropenis.

In female fetuses, the levels of gonadotropins are much higher than in males [11], and this sex hormonal difference is thought to be due to the negative effects of fetal testicular hormone [12]. LH stimulates the theca cells in the fetal ovaries to produce testosterone and FSH induces aromatase activity in the ovarian granulosa cells to convert testosterone to estradiol [5], even though the placenta is the main source of fetal estrogen [13]. Placental production of estrogen, which gradually increases until the end of gestation, and estradiol levels increase in both maternal and fetal circulation [9]. The absence of AMH develops the Müllerian ducts into the fallo- 
pian tubes, uterus, and the upper portion of the vagina. However, the role of gonadotropins in fetal life is not well understood. Based on the results of a study of anencephalic female fetuses, ovarian development is independent of the HPG axis until the 7th month of gestation, but gonadotropin appears to play an important role in follicular growth later on [14]. In addition, prematurely born girls who are not exposed to the highest intrauterine estrogen level in late pregnancy have smaller uteri than full-term girls at birth [6]. Therefore, elevated estradiol levels in late pregnancy may play a role in uterine growth.

This increase in fetal LH and FSH levels is the first instance of HPG axis activation in a lifespan. However, the secretion of gonadotropins gradually decreases toward birth because of the suppressive effect of the high concentrations of placental hormones [15], and the gonadotropins and testosterone/estradiol levels are very low at the end of gestation [5].

\section{Infancy: minipuberty}

After birth, the HPG axis is transiently activated again, and gonadotropin levels increase over a period of time after birth, denoted minipuberty $[5,15]$. This is the second instance of HPG axis activation in life. The increase in gonadotropin levels persists until 6 to 9 months of age, and FSH levels in girls remain elevated until 3 to 4 years of age [8]. In boys, elevated gonadotropin levels are associated with increases in testosterone, INSL-3, inhibin B, and AMH $[16,17]$, and these increased sex steroid levels are also important for genital virilization and fertility during the fetal period. Testosterone levels increase after birth, similar to gonadotropin levels, reaching a peak between 1 and 3 months of age to a degree slightly below adult levels [18]. Testosterone levels at this time are associated with penile growth, which increase up until the age of 3 years [19]. In addition, postnatal testosterone levels have been associated with neurobehavioral development, such as male-type behaviors in infants [20]. Furthermore, elevated FSH levels are positively correlated with testicular growth, which indicates increased total germ cells and Sertoli cell numbers [21]. Thereafter, testosterone levels gradually decrease until 6 months of age and remain low until puberty, at nearly unmeasurable levels [5]. Therefore, minipuberty in boys is also a critical period in the formation of the male reproductive tract as well as male behavior $[20,22]$.

The HPG axis is activated in girls as well as in boys, but the association between elevated gonadotropin and sex steroids and the development of the female reproductive organs in minipuberty remains unclear [5]. Estradiol levels are low during the 1st week of age and then increase and fluctuate, changes that are associated with ovarian follicular development [6], especially cyclic maturation and atrophy of ovarian follicles [12]. In addition, because the mammary glands, which are not sexually different at birth, are larger in girls than in boys in infancy, postnatal estradiol levels have biological effects on mammary glands in girls [6].

\section{Puberty}

The HPG axis is quiescent during childhood [23] and then reactivated during puberty, which is the third activation. The reactivation of the HPG axis is characterized by pulsatile release of the $\mathrm{GnRH}$, marking the onset of puberty. The mechanism for the pulsatile release of GnRH is unknown; however, recent studies have identified kisspeptin, which is markedly increased during puberty, as a potential regulator of $\mathrm{GnRH}$ secretion [24]. This GnRH pulse leads to pulsatile LH and FSH release, which is a surrogate marker of $\mathrm{GnRH}$ pulsatile release and puberty onset. LH and FSH pulses stimulate the gonads for sexual maturation and reproduction. More specifically, FSH stimulates the immature Sertoli cells and spermatogonia for proliferation, and LH stimulates the Leydig cells to produce testosterone in boys. Increased intragonadal testosterone levels initiate spermatogenesis [3]. In girls, gonadotropins induce follicular maturation and lead to ovulation. FSH stimulates secondary ovarian follicle recruitment and estradiol secretion.

Testosterone and estradiol induce secondary sexual characteristics in both boys and girls. The first pubertal signs are testicular enlargement in boys and breast development in girls. These manifests occur around the age of 11.5 years (ranging from 9 to 14) in boys and 10 years (ranging from 8 to 13) in girls. Subsequently, pubic and axillary hairs begin to appear, and a period of growth spurt occurs in both sexes. In addition, the voice of boys is deepened and menarche occurs in girls [3]. Therefore, a deficiency in any one of the hormones of the HPG axis, including kisspeptin, $\mathrm{GnRH}, \mathrm{LH}$, and $\mathrm{FSH}$, impairs the development of puberty and causes delayed puberty and/or infertility.

\section{CLINICAL CHARACTERISTIC AND BIOCHEMICAL PROFILE OF CHH}

In $\mathrm{CHH}$, the $\mathrm{GnRH} /$ gonadotropin secretion is low. $\mathrm{CHH}$ is divided into three subtypes: isolated gonadotropin deficiency, Kallmann syndrome, and syndromic forms of $\mathrm{CHH}$ [4]. Isolated gonadotropin deficiency is exclusively caused by $\mathrm{GnRH}$ 
and gonadotropin deficiencies. The cause of Kallmann syndrome is also a GnRH and gonadotropin deficiency, but it is different in that the clinical symptoms usually involve partial or complete loss of olfactory function. Syndromic forms of $\mathrm{CHH}$, such as coloboma, heart defect, atresia choanae, retarded growth and development, genital hypoplasia, ear anomalies/deafness (CHARGE) syndrome, Dandy-Walker syndrome, and Gordon Holmes syndrome, have clinical manifestations with hypogonadotropic hypogonadism and the typical clinical features of a particular syndrome.

As the clinical presentation of $\mathrm{CHH}$ varies with lifespan, we will summarize the clinical characteristics and hormonal profile of $\mathrm{CHH}$ according to the life cycle in detail.

\section{Neonates to infants}

In male infants, lack of activation of the HPG axis during the fetal to infant period (absent minipuberty) may cause cryptorchidism and/or a micropenis, and these features can provide indications of $\mathrm{GnRH}$ deficiency [5]. As mentioned earlier, penile and testicular growth is strongly associated with sex steroid levels and gonadotropin levels $[19,21]$. Of course, placental hCG stimulates the testes and penile growth, but pituitary LH is needed for further masculinization of the external genitalia. On the other hand, hypospadias rarely occur in $\mathrm{CHH}$ because placental $\mathrm{hCG}$ secretion is sufficient to produce the androgens required for urethral closure [25]. However, there are no specific clinical signs in female infants with $\mathrm{CHH}$.

\section{Adolescents}

$\mathrm{CHH}$ is characterized by delayed pubertal development during adolescence. Delayed puberty is defined as the absence of pubertal signs, such as testicular enlargement in boys and breast development in girls, at a standard deviation of 2 to 2.5 years later than the population mean [26]. Traditionally, the age cut-off for delayed puberty is 14 years in boys and 13 years in girls. However, since pubertal timing is different among racial and ethnic groups and the onset of puberty occurs earlier in most countries, new age criteria will have to be applied [26]. Adolescents with $\mathrm{CHH}$ tend to have prepubertal testicular volume (i.e., $<4 \mathrm{~mL}$ ) when male and the absence of breast development (i.e., Tanner stage 1 ) when female. In addition, the assessment of the rate of puberty progression should also be considered to identify delayed puberty [3]. Adolescents with $\mathrm{CHH}$ also present with arrested puberty, such as undervirilization in boys and arrested breast development or primary amenorrhea in girls $[3,27,28]$. Skeletal maturation is normal but delayed in the absence of a distinct pubertal growth spurt. Therefore, poor growth velocity and eunuchoidal proportions are often observed. Since these clinical features are similar to those of constitutional delay of growth and puberty (CDGP), it is necessary to differentiate between CHH and CDGP. At this time, the presence of micropenis and/or cryptorchidism (or past history of cryptorchidism and orchiopexy) suggests $\mathrm{CHH}$ rather than CDGP [3].

\section{Young adults}

Similar to adolescents, adults with $\mathrm{CHH}$ have no secondary sexual features and/or incomplete sexual maturation (e.g., facial and axillary hair growth, deepening of the voice in males, and little or no breast development, and primary amenorrhea in females). Since pubic hair is partly controlled by adrenal androgens, pubic hair develops around Tanner stages II to III. In addition, decreased muscle mass, diminished libido, erectile dysfunction, and infertility are present [29].

\section{Biochemical profile of $\mathrm{CHH}$}

$\mathrm{CHH}$ is characterized by inappropriately low serum gonadotropin levels in patients with low sex steroid levels. After minipuberty, the HPG axis is quiescent and gonadotropin levels are normally unmeasurable until puberty. Therefore, the period of minipuberty is an important opportunity to identify $\mathrm{CHH}$. Measuring serum gonadotropins, testosterone, and inhibin $B$ at 4 to 8 weeks of life is recommended for the differential diagnosis of sexual development disorders or $\mathrm{CHH}$ in male infants, and this provides clinical evidence of $\mathrm{CHH}$ without the need for GnRH stimulation tests in infants [5]. In addition, female infants born to parents with $\mathrm{CHH}$ should measure these hormone levels, and FSH levels seem to be the most sensitive marker of $\mathrm{CHH}$ [30].

Before puberty, diagnosis of $\mathrm{CHH}$ is very difficult, as this period represents physiologically low $\mathrm{GnRH}$ /gonadotropin levels. Undetectable FSH levels (not LH levels) or absence of response to a $\mathrm{GnRH}$ stimulation test might suggest $\mathrm{CHH}$ in prepubertal children [3]. In adolescents and adults with $\mathrm{CHH}$, even though sex steroid levels are low (e.g., total testosterone $<100 \mathrm{ng} / \mathrm{dL}$ in men and estradiol $<50 \mathrm{pg} / \mathrm{mL}$ in women), serum gonadotropin levels are typically inappropriately low or normal [29]. In adolescence, it is difficult to differentiate between $\mathrm{CHH}$ and CDGP. Severe forms of $\mathrm{CHH}$ can be diagnosed by GnRH stimulation tests in the absence of a response, but partial forms of $\mathrm{CHH}$ cannot be differentiated from CDGP with GnRH stimulation tests. The combination of $\mathrm{GnRH}$ and hCG stimulation tests or measurement of inhibin 
B, AMH, and INSL-3 levels have been proposed for differential diagnosis. Inhibin B is an indicator of Sertoli cell number and is related to the testicular volume [3], and INSL-3 is regulated by $\mathrm{LH}$ and reflects a relatively mature Leydig cell [31]. Therefore, inhibin B and INSL-3 levels might be good markers of testicular function, Sertoli cells, and Leydig cells, respectively $[31,32]$. As kisspeptin is a regulator of $\mathrm{GnRH}$ secretion, exogenous kisspeptin administration might also be a diagnostic test that would fail to induce a response in $\mathrm{CHH}$. However, there is no gold standard diagnostic test developed currently [3].

\section{Imaging findings of $\mathrm{CHH}$}

Although $\mathrm{CHH}$ is characterized by $\mathrm{GnRH} /$ gonadotropin deficiency, there are no structural abnormalities in the hypothalamus and pituitary in sella magnetic resonance imaging. However, aplasia or hypoplasia of the olfactory bulb is usually observed in Kallmann syndrome.

\section{Other findings}

Olfactory function can be evaluated using a formal diagnostic smell test. Individuals with $\mathrm{CHH}$ with anosmia or hyposmia are diagnosed with Kallmann syndrome, while normosmia individuals with $\mathrm{CHH}$ are diagnosed with isolated gonadotropin deficiency [29]. Other phenotypes such as cleft palate, sensorineural deafness, dental agenesis, renal agenesis, and bimanual synkinesis suggest a syndromic form of $\mathrm{CHH}$ [3].

\section{GENETIC ASPECTS}

Genetic testing is important for the diagnosis, prognosis, and genetic counseling of $\mathrm{CHH}$, and infants born to parents with $\mathrm{CHH}$ should have their sex hormones monitored and receive genetic testing [3]. First, before conducting genetic testing, examination of pedigrees in detail and identification of inheritance patterns are needed. If male members in the maternal line reveal the disease phenotype and no male-tomale transmission is observed, we can suspect X-linked inheritance and Kallmann syndrome due to anosmin 1 (ANOS1) gene mutations [3]. However, incomplete penetrance and heterogeneity of the disease phenotype, even in identical genes or mutations, should be considered [33-35]. In addition, more than 30 genes are known to be associated with $\mathrm{CHH}$, and oligogenic forms of $\mathrm{CHH}$ have also been identified $[35,36]$. Therefore, testing techniques such as NGS are required unless the causative gene is clear, such as with a fami- ly member with an identified causative gene. Genetic causes have been identified in about $50 \%$ of cases classified as "idiopathic" after the development of genetic techniques such as NGS $[3,7]$. However, the genetic causes for the other half of $\mathrm{CHH}$ cases remain unknown.

\section{RELATED GENES ACCORDING TO BIOLOGY OR THE GNRH NEURONAL SYSTEM}

During early embryogenesis, GnRH neurons originate in the olfactory placode and migrate into the hypothalamic area of the brain [37]. At birth, GnRH neurons in their final destination project into the median eminence, where they release $\mathrm{GnRH}$ into the hypophyseal portal vasculature [38]. GnRH regulates gonadotropin synthesis and release via the $\mathrm{GnRH}$ receptor in gonadotropic cells in the anterior pituitary gland. Gonadotropins such as LH and FSH control gonadal maturation as well as production and secretion of gonadal sex steroids. More than 30 genes involved in this process have already been identified; if there is a defect in any of the genes involved, $\mathrm{CHH}$ might occur. Table 1 summarizes the related genes by classifying them according to their main pathological mechanisms.

\section{TREATMENT}

In boys with $\mathrm{CHH}$, testicular descent and penile growth are the focus of treatment. Because cryptorchidism can adversely affect fertility, surgical correction is required within 6 to 12 months of age $[39,40]$. Minipuberty is an opportunity for treatment with low-dose testosterone (testosterone esters or dihydrotestosterone) to increase penile growth [41]. As the duration of treatment is short, such treatment during minipuberty is effective and well-tolerated without virilization or disturbances of growth [3,41]. Gonadotropin (LH and FSH) therapy in minipuberty has also been attempted [4]. Although this approach has several benefits in terms of stimulating the proliferation of immature Sertoli cells and spermatogonia, due to the limited number of studies and participants, further research is needed to evaluate the effectiveness and long-term outcomes of gonadotropin treatments [3].

During adolescence, the goal of treatment is to induce normal secondary sexual characteristics, including virilization or estrogenization, growth spurt and bone health, gonadal maturation with future fertility, and psychological well-being. In males, testosterone injection, oral testosterone, and transdermal testosterone application can be used. Depend- 
PRECISION AND FUTURE MIEDICINE

Congenital hypogonadotropic hypogonadism

Table 1. Genetics of congenital hypogonadotropic hypogonadism

\begin{tabular}{|c|c|c|c|c|c|}
\hline Main pathological mechanism & Gene name & $\begin{array}{c}\text { Gene } \\
\text { symbol }\end{array}$ & Locus & OMIM & Inheritance \\
\hline \multirow[t]{13}{*}{ GnRH migration/axon guidance } & Anosmin 1 & ANOS1 (KAL1) & Xp22.31 & 300836 & XLR \\
\hline & Anti-Müllerian hormone & $A M H$ & $19 q 13.3$ & 600951 & $A D$ \\
\hline & Anti-Müllerian hormone type II receptor & AMHR2 & $12 q 13.13$ & 600956 & $A D$ \\
\hline & DCC netrin 1 receptor & $D C C$ & $18 q 21.2$ & 120470 & AD, olig \\
\hline & FEZ family zinc finger protein 1 & FEZF1 & $7 q 31.32$ & 613301 & AR \\
\hline & Netrin 1 & NTN1 & $17 q 13.1$ & 601614 & AD, olig \\
\hline & Neuron derived neurotrophic factor & NDNF & $4 q 27$ & 616506 & $A D$ \\
\hline & Prokineticin 2 & PROK2 & $3 p 13$ & 607002 & AR, AD, olig \\
\hline & Prokeneticin receptor 2 & PROKR2 & $20 \mathrm{p} 12.3$ & 607123 & AR, AD, olig \\
\hline & Semaphorin $3 \mathrm{~A}$ & SEMA3A & $7 \mathrm{p} 12.1$ & 603961 & AD, olig \\
\hline & Semaphorin 3E & SEMA3E & $7 q 21.11$ & 608166 & Olig \\
\hline & Sry-box 10 & SOX10 & $22 q 13.1$ & 602229 & $A D$ \\
\hline & Tubulin, beta-3 & TUBB3 & $16 q 24.3$ & 602661 & $A D$ \\
\hline \multirow[t]{10}{*}{ GnRH neuron specification } & Chromodomain helicase DNA binding protein 7 & CHD7 & $8 q 12.2$ & 608892 & AR, AD, olig \\
\hline & Fibroblast growth factor 8 & FGF8 & $10 \mathrm{q} 24.32$ & 600483 & Olig \\
\hline & Fibroblast growth factor 17 & FGF17 & $8 q 21.3$ & 603725 & Olig \\
\hline & Fibroblast growth factor receptor 1 & FGFR1 & 8p11.23 & 136350 & AR, AD, olig \\
\hline & Interleukin 17 receptor $D$ & IL17RD & $3 p 14.3$ & 606807 & Olig \\
\hline & Immunoglobulin superfamily, member 10 & IGSF10 & $3 q 25.1$ & 617351 & $A D$ \\
\hline & Beta-Klotho & $K L B$ & $4 \mathrm{p} 14$ & 611135 & $A D$ \\
\hline & Nuclear receptor subfamily 0 , group B, member 1 & $N R O B 1(D A X 1)$ & Xp21.2 & 300473 & $\mathrm{XLR}$ \\
\hline & Sry-box 2 & SOX2 & $3 q 26.33$ & 184429 & AR \\
\hline & WD repeat-containing protein 11 & WDR11 & $10 q 26.12$ & 606417 & AD. olig \\
\hline \multirow[t]{4}{*}{ GnRH neuron activation } & Kiss 1 metastasis suppressor & KISS1 & $1 q 32.1$ & 603286 & AR \\
\hline & Kiss 1 receptor & KISSIR & 19p13.3 & 604161 & AR \\
\hline & Tachykinin 3 & TAC3 & $12 q 13.3$ & 162330 & $A R$ \\
\hline & Tachykinin receptor 3 & TACR3 & $4 q 24$ & 162332 & AR, olig \\
\hline \multirow[t]{2}{*}{ GnRH function } & Gonadotropin releasing hormone 1 & GnRH1 & 821.2 & 152760 & AR, olig \\
\hline & Gonadotropin releasing hormone receptor & $G n R H R$ & $4 q 13.2$ & 138850 & AR, olig \\
\hline \multirow[t]{7}{*}{ Gonadotroph specification } & Gli-Kruppel family member 2 & GLI2 & $2 q 14.2$ & 165230 & $A D$ \\
\hline & Homeobox gene expressed in ES cells & HESX1 & $3 p 14.3$ & 601802 & $A D, A R$ \\
\hline & Lim homeobox gene 3 & LHX3 & $9 q 34.3$ & 600577 & AR \\
\hline & Lim homeobox gene 4 & LHX4 & $1 \mathrm{q} 25.2$ & 602146 & $A D$ \\
\hline & Orthodenticle, drosophila, homolog Of, 2 & OTX2 & $14 q 22.3$ & 600037 & $A D$ \\
\hline & SRY-box 3 & SOX3 & $\mathrm{Xq} 27.1$ & 313430 & $\mathrm{XLR}$ \\
\hline & Prop paired like homeobox 1 & PROP1 & $5 q 35.3$ & 601538 & AR \\
\hline \multirow[t]{3}{*}{ Gonadotropin secretion or action } & Follicle stimulating hormone, beta polypeptide & FSHB & $11 \mathrm{p} 14.1$ & 136530 & AR \\
\hline & Luteinizing hormone, beta polypeptide & $L H B$ & $19 q 13.33$ & 152780 & $A R$ \\
\hline & Proprotein convertase, subtilisin/kexintype, 1 & PCSK1 & $5 q 15$ & 162150 & AR \\
\hline
\end{tabular}

OMIM, Online Mendelian Inheritance in Man; GnRH, gonadotropin-releasing hormone; XLR, X-linked recessive; AD, autosomal dominant; olig, oligogenic; AR, autosomal recessive. 
ing on the protocol, starting treatment with low-dose testosterone $(50 \mathrm{mg}$ of testosterone enanthate monthly, $40 \mathrm{mg}$ oral testosterone undecanoate daily, or $10 \mathrm{mg}$ transdermal testosterone every other day) at around age 12 and gradually increasing the dose to full adult dosing over 18 to 24 months is possible $[42,43]$. However, testosterone treatment does not induce gonadal maturation or fertility. Therefore, pulsatile GnRH or gonadotropin therapy (hCG alone or in combination with FSH) can be considered [44]. In females, puberty can be induced by low-dose oral ( $0.1 \mathrm{mg}$ daily) or transdermal estradiol $(0.05$ to $0.07 \mu \mathrm{g} / \mathrm{kg})$ administration from the age of 10 years. The estradiol dose gradually increases from 12 to 24 months (or after the first menstrual bleeding) to the adult dose and then progestin is added [3].

In adults, the goal of treatment is to maintain sex steroid levels in the normal range and to induce fertility. In males, the frequency or dose of testosterone injections should be adjusted by trough serum testosterone level in order to aim above the lower limit of the normal range and to avoid hypogonadism between injections [3]. Spermatogenesis can be induced by subcutaneous gonadotropin injections (hCG and FSH) 2 to 3 times per week. If the testicular volume is prepubertal, 1,000 to 1,500 IU of hCG and 75 to $160 \mathrm{IU}$ of FSH 2 to 3 times a week is administered. However, hCG monotherapy can induce spermatogenesis if the testicular volume is greater than $4 \mathrm{~mL}$ and there is no history of cryptorchidism. Moreover, cryptorchidism, prepubertal testicular volume, and low serum inhibin $B$ levels indicate poor fertility prognosis [45, 46]. In females, oral estradiol at a dose of 1 to $2 \mathrm{mg}$ is administered as a maintenance dose with a cyclic progesterone (200 mg for 14 days of the cycle). Estrogen treatment increases uterine size, and combined cyclic therapy with estrogen and progesterone induces monthly menstruation. However, since this therapy cannot induce ovulation, gonadotropins are required for fertility [3].

\section{CONCLUSION}

Since $\mathrm{CHH}$ is a clinically and genetically heterogeneous disease, diagnosis and appropriate treatment are usually difficult. Clinical characteristics and biochemical profiles appear to differ depending on the period of sexual characteristics and reproduction development, especially during the period of HPG axis activation. In addition, treatment goals differ according to developmental stage. Therefore, it is important to know the clinical features of each developmental period, and a profound understanding of normal development can help in the diagnosis and treatment of $\mathrm{CHH}$.

\section{CONFLICTS OF INTEREST}

No potential conflict of interest relevant to this article was reported.

\section{ORCID}

Ahreum Kwon https://orcid.org/0000-0002-9692-2135

Ho-Seong Kim https://orcid.org/0000-0003-1135-099X

\section{AUTHOR CONTRIBUTIONS}

Conception or design: AK, HSK.

Acquisition, analysis, or interpretation of data: AK.

Drafting the work or revising: AK.

Final approval of the manuscript: AK, HSK.

\section{REFERENCES}

1. Neocleous V, Fanis P, Toumba M, Tanteles GA, Schiza M, Cinarli F, et al. GnRH deficient patients with congenital hypogonadotropic hypogonadism: novel genetic findings in ANOS1, RNF216, WDR11, FGFR1, CHD7, and POLR3A genes in a case series and review of the literature. Front Endocrinol (Lausanne) 2020;11:626.

2. Cangiano B, Swee DS, Quinton R, Bonomi M. Genetics of congenital hypogonadotropic hypogonadism: peculiarities and phenotype of an oligogenic disease. Hum Genet 2021;140:77-111.

3. Boehm U, Bouloux PM, Dattani MT, de Roux N, Dode C, Dunkel L, et al. Expert consensus document: European Consensus Statement on congenital hypogonadotropic hypogonadism: pathogenesis, diagnosis and treatment. Nat Rev Endocrinol 2015;11:547-64.

4. Bouvattier C, Maione L, Bouligand J, Dode C, GuiochonMantel A, Young J. Neonatal gonadotropin therapy in male congenital hypogonadotropic hypogonadism. Nat Rev Endocrinol 2011;8:172-82.

5. Renault $\mathrm{CH}$, Aksglaede L, Wojdemann D, Hansen AB, Jensen RB, Juul A. Minipuberty of human infancy: a window of opportunity to evaluate hypogonadism and differences of sex development? Ann Pediatr Endocrinol Metab 2020; 25:84-91.

6. Kuiri-Hanninen T, Haanpaa M, Turpeinen U, Hamalainen E, Seuri R, Tyrvainen E, et al. Postnatal ovarian activation 
has effects in estrogen target tissues in infant girls. J Clin Endocrinol Metab 2013;98:4709-16.

7. Young J, Xu C, Papadakis GE, Acierno JS, Maione L, Hietamaki J, et al. Clinical management of congenital hypogonadotropic hypogonadism. Endocr Rev 2019;40:669-710.

8. Reyes FI, Boroditsky RS, Winter JS, Faiman C. Studies on human sexual development. II. Fetal and maternal serum gonadotropin and sex steroid concentrations. J Clin Endocrinol Metab 1974;38:612-7.

9. Troisi R, Potischman N, Roberts JM, Harger G, Markovic N, Cole B, et al. Correlation of serum hormone concentrations in maternal and umbilical cord samples. Cancer Epidemiol Biomarkers Prev 2003;12:452-6.

10. Lee MM, Donahoe PK. Mullerian inhibiting substance: a gonadal hormone with multiple functions. Endocr Rev 1993; 14:152-64.

11. Kaplan SL, Grumbach MM. The ontogenesis of human foetal hormones. II. Luteinizing hormone (LH) and follicle stimulating hormone (FSH). Acta Endocrinol (Copenh) 1976;81: 808-29.

12. Kuiri-Hanninen T, Sankilampi U, Dunkel L. Activation of the hypothalamic-pituitary-gonadal axis in infancy: minipuberty. Horm Res Paediatr 2014;82:73-80.

13. Forabosco A, Sforza C. Establishment of ovarian reserve: a quantitative morphometric study of the developing human ovary. Fertil Steril 2007;88:675-83.

14. Baker TG, Scrimgeour JB. Development of the gonad in normal and anencephalic human fetuses. J Reprod Fertil 1980;60:193-9.

15. Andersson AM, Toppari J, Haavisto AM, Petersen JH, Simell T, Simell O, et al. Longitudinal reproductive hormone profiles in infants: peak of inhibin $B$ levels in infant boys exceeds levels in adult men. J Clin Endocrinol Metab 1998;83:675-81.

16. Aksglaede L, Sorensen K, Boas M, Mouritsen A, Hagen CP, Jensen RB, et al. Changes in anti-Mullerian hormone (AMH) throughout the life span: a population-based study of 1027 healthy males from birth (cord blood) to the age of 69 years. J Clin Endocrinol Metab 2010;95:5357-64.

17. Bay K, Virtanen HE, Hartung S, Ivell R, Main KM, Skakkebaek NE, et al. Insulin-like factor 3 levels in cord blood and serum from children: effects of age, postnatal hypothalamic-pituitary-gonadal axis activation, and cryptorchidism. J Clin Endocrinol Metab 2007;92:4020-7.

18. Winter JS, Faiman C, Hobson WC, Prasad AV, Reyes FI. Pituitary-gonadal relations in infancy. I. Patterns of serum gonadotropin concentrations from birth to four years of age in man and chimpanzee. J Clin Endocrinol Metab 1975; 40:545-51.

19. Boas M, Boisen KA, Virtanen HE, Kaleva M, Suomi AM, Schmidt IM, et al. Postnatal penile length and growth rate correlate to serum testosterone levels: a longitudinal study of 1962 normal boys. Eur J Endocrinol 2006;154:125-9.

20. Lamminmaki A, Hines M, Kuiri-Hanninen T, Kilpelainen L, Dunkel L, Sankilampi U. Testosterone measured in infancy predicts subsequent sex-typed behavior in boys and in girls. Horm Behav 2012;61:611-6.

21. Kuiri-Hanninen T, Seuri R, Tyrvainen E, Turpeinen U, Hamalainen E, Stenman UH, et al. Increased activity of the hypothalamic-pituitary-testicular axis in infancy results in increased androgen action in premature boys. J Clin Endocrinol Metab 2011;96:98-105.

22. Swee DS, Quinton R. Congenital hypogonadotrophic hypogonadism: minipuberty and the case for neonatal diagnosis. Front Endocrinol (Lausanne) 2019;10:97.

23. Waldhauser F, Weissenbacher G, Frisch H, PollakA. Pulsatile secretion of gonadotropins in early infancy. Eur J Pediatr 1981;137:71-4.

24. Seminara SB, Messager S, Chatzidaki EE, Thresher RR, Acierno JS Jr, Shagoury JK, et al. The GPR54 gene as a regulator of puberty. N Engl J Med 2003;349:1614-27.

25. Main KM, Schmidt IM, Skakkebaek NE. A possible role for reproductive hormones in newborn boys: progressive hypogonadism without the postnatal testosterone peak. J Clin Endocrinol Metab 2000;85:4905-7.

26. Palmert MR, Dunkel L. Clinical practice: delayed puberty. N Engl J Med 2012;366:443-53.

27. Young J. Approach to the male patient with congenital hypogonadotropic hypogonadism. J Clin Endocrinol Metab 2012;97:707-18.

28. Yoon JY, Cheon CK. Evaluation and management of amenorrhea related to congenital sex hormonal disorders. Ann Pediatr Endocrinol Metab 2019;24:149-57.

29. Balasubramanian R, Crowley WF Jr. Isolated gonadotropin-releasing hormone (GnRH) deficiency. In: Adam MP, Ardinger HH, Pagon RA, Wallace SE, Bean LJH, Mirzaa G, et al., editors. GeneReviews. Seattle (WA): University of Washington, Seattle; 2007. Available from: https://www. ncbi.nlm.nih.gov/books/NBK1334.

30. Chellakooty M, Schmidt IM, Haavisto AM, Boisen KA, Damgaard IN, Mau C, et al. Inhibin A, inhibin B, follicle-stimulating hormone, luteinizing hormone, estradiol, and sex hormone-binding globulin levels in 473 healthy infant girls. J Clin Endocrinol Metab 2003;88:3515-20. 
31. Johansen ML, Anand-Ivell R, Mouritsen A, Hagen CP, Mieritz MG, Soeborg T, et al. Serum levels of insulin-like factor 3, anti-Mullerian hormone, inhibin B, and testosterone during pubertal transition in healthy boys: a longitudinal pilot study. Reproduction 2014;147:529-35.

32. Pitteloud N, Hayes FJ, Boepple PA, DeCruz S, Seminara SB, MacLaughlin DT, et al. The role of prior pubertal development, biochemical markers of testicular maturation, and genetics in elucidating the phenotypic heterogeneity of idiopathic hypogonadotropic hypogonadism. J Clin Endocrinol Metab 2002;87:152-60.

33. Choe J, Kim JH, Kim YA, Lee J. Dizygotic twin sisters with normosmic idiopathic hypogonadotropic hypogonadism caused by an FGFR1 gene variant. Ann Pediatr Endocrinol Metab 2020;25:192-7.

34. Pitteloud N, Acierno JS Jr, Meysing AU, Dwyer AA, Hayes FJ, Crowley WF Jr. Reversible Kallmann syndrome, delayed puberty, and isolated anosmia occurring in a single family with a mutation in the fibroblast growth factor receptor 1 gene. J Clin Endocrinol Metab 2005;90:1317-22.

35. Maione L, Dwyer AA, Francou B, Guiochon-Mantel A, Binart N, Bouligand J, et al. Genetics in endocrinology: genetic counseling for congenital hypogonadotropic hypogonadism and Kallmann syndrome: new challenges in the era of oligogenism and next-generation sequencing. Eur J Endocrinol 2018;178:R55-80.

36. Sykiotis GP, Plummer L, Hughes VA, Au M, Durrani S, Nayak-Young $S$, et al. Oligogenic basis of isolated gonadotropin-releasing hormone deficiency. Proc Natl Acad Sci U S A 2010;107:15140-4.

37. Wierman ME, Kiseljak-Vassiliades K, Tobet S. Gonadotropin-releasing hormone $(\mathrm{GnRH})$ neuron migration: initiation, maintenance and cessation as critical steps to ensure normal reproductive function. Front Neuroendocrinol 2011;32:43-52.
38. Bianco SD, Kaiser UB. The genetic and molecular basis of idiopathic hypogonadotropic hypogonadism. Nat Rev Endocrinol 2009;5:569-76.

39. van Brakel J, Kranse R, de Muinck Keizer-Schrama SM, Hendriks AE, de Jong FH, Bangma CH, et al. Fertility potential in men with a history of congenital undescended testes: a long-term follow-up study. Andrology 2013;1: 100-8.

40. Penson D, Krishnaswami S, Jules A, McPheeters ML. Effectiveness of hormonal and surgical therapies for cryptorchidism: a systematic review. Pediatrics 2013;131:e1897907.

41. Hatipoglu N, Kurtoglu S. Micropenis: etiology, diagnosis and treatment approaches. J Clin Res Pediatr Endocrinol 2013;5:217-23.

42. Dunkel L, Quinton R. Transition in endocrinology: induction of puberty. Eur J Endocrinol 2014;170:R229-39.

43. Lawaetz JG, Hagen CP, Mieritz MG, Blomberg Jensen M, Petersen JH, Juul A. Evaluation of 451 Danish boys with delayed puberty: diagnostic use of a new puberty nomogram and effects of oral testosterone therapy. J Clin Endocrinol Metab 2015;100:1376-85.

44. Shiraishi K, Oka S, Matsuyama H. Assessment of quality of life during gonadotrophin treatment for male hypogonadotrophic hypogonadism. Clin Endocrinol (Oxf) 2014; 81:259-65.

45. Liu PY, Baker HW, Jayadev V, Zacharin M, Conway AJ, Handelsman DJ. Induction of spermatogenesis and fertility during gonadotropin treatment of gonadotropin-deficient infertile men: predictors of fertility outcome. J Clin Endocrinol Metab 2009;94:801-8.

46. Dwyer AA, Raivio T, Pitteloud N. Gonadotrophin replacement for induction of fertility in hypogonadal men. Best Pract Res Clin Endocrinol Metab 2015;29:91-103. 